\title{
Polydimethylsiloxane micro-channels application for the study of dynamic wetting of nano-etched silicon surfaces based on acoustic characterization method
}

\author{
A. Salhab, Julien Carlier, Pierre Campistron, M. Neyens, M. Toubal, \\ Bertrand Nongaillard, V. Thomy
}

\section{To cite this version:}

A. Salhab, Julien Carlier, Pierre Campistron, M. Neyens, M. Toubal, et al.. Polydimethylsiloxane micro-channels application for the study of dynamic wetting of nano-etched silicon surfaces based on acoustic characterization method. 15th International Symposium on Ultra Clean Processing of Semiconductor Surfaces, UCPSS 2021, Session 6 - Wet processing in narrow spaces and pattern collapse, Apr 2021, Virtual, Unknown Region. pp.143-149, 10.4028/www.scientific.net/SSP.314.143 . hal-03362264

\section{HAL Id: hal-03362264 \\ https://hal.archives-ouvertes.fr/hal-03362264}

Submitted on 4 Oct 2021

HAL is a multi-disciplinary open access archive for the deposit and dissemination of scientific research documents, whether they are published or not. The documents may come from teaching and research institutions in France or abroad, or from public or private research centers.
L'archive ouverte pluridisciplinaire HAL, est destinée au dépôt et à la diffusion de documents scientifiques de niveau recherche, publiés ou non, émanant des établissements d'enseignement et de recherche français ou étrangers, des laboratoires publics ou privés. 


\title{
Polydimethylsiloxane Micro-Channels Application for the Study of Dynamic Wetting of Nano-Etched Silicon Surfaces Based on Acoustic Characterization Method
}

\author{
A. Salhab ${ }^{1,2, a^{*}}$, J. Carlier ${ }^{1, b}$, P. Campistron ${ }^{1}$, M. Neyens, M. Toubal ${ }^{1}$, \\ B. Nongaillard ${ }^{1}$, V. Thomy ${ }^{3, c}$ \\ ${ }^{1}$ Univ. Polytechnique Hauts-de-France, CNRS, Univ. Lille, ISEN, Centrale Lille, UMR 8520 - IEMN \\ - Institut d'Électronique de Microélectronique et de Nanotechnologie, DOAE - Département d'Opto- \\ Acousto-Électronique, F-59313 Valenciennes, France \\ ${ }^{2}$ STMicroelectronics, 850 rue Monnet, F-38926 Crolles, France \\ ${ }^{3}$ Institute of Electronics, Microelectronics and Nanotechnology, Univ. Lille, UMR 8520 - IEMN, \\ F-59000 Lille, France \\ aAbbas.salhab@etu.uphf.fr, bJulien.carlier@uphf.fr, ‘Vincent.thomy@univ-lille.fr
}

Keywords: Micro and Nano-technology, Wetting, Surface cleaning, Microelectronics, Nondestructive testing, Acoustics, Piezoelectric transducers, Microfluidics, Deep trench isolation

\begin{abstract}
Efficient cleaning of contaminations in the semiconductor industry is a determining factor in ensuring the good quality of the electronics products. We present here the dynamic wetting characterization of a fluid on top of Deep Trench Isolation (DTI) structures using ultra-high frequency acoustic method. The dynamics of the fluid will be established using a PolyDiMethylSiloxane (PDMS) micro-channel placed on top of the structures, in order to obtain conditions as close as possible to those used in the industrial process. Wetting state of the DTI structures is determined based on the measured acoustic reflection coefficient.
\end{abstract}

\section{Introduction}

In the microelectronics industry the tendency for miniaturization of the electronic components has led to the fabrication of micro and nanostructures with high aspect ratios (for example structures of hundreds of nanometers wide and tens of micrometers height). With these increasing aspect ratios it's becoming more and more difficult to achieve wet cleaning of these etched silicon structures [1] and to remove non-desired particles which can lead to defective electronic products.

We developed an acoustic method [2, 3] using ultra-high frequency $(5 \mathrm{GHz})$ to detect the penetration of the liquid to the bottom of the etched structure and hence get information about the efficiency of the wetting (cleaning) states. Our previous results have been obtained under static wetting conditions (droplet based) while the industrial cleaning process uses a liquid dispensed in a form of jet on a rotating wafer. Thus, in order to have experimental conditions closer to industrial practice, a PDMS based micro-channel has been placed on the top of the etched silicon wafer matrix (Fig. 1 and Fig. 2) in a manner that the DTI trenches are perpendicular to the micro-channel. The industrial cleaning process is done by rotating a silicon wafer and dispensing the fluid in a form of jet on top of this rotating wafer. Due to the complexity of the industrial process we will not implement the rotation. Instead we will use micro-channel to establish a dynamic liquid flow with conditions as close as possible to the industrial process and get information on the wetting dynamic of these high aspect ratio structures. Information from the industrial process has been obtained and used in hydrodynamic calculations for our PDMS micro-channel system and are presented in the next section.

\section{Experimental Setup}

The characterization acoustic method that we developed [2] is represented in Fig. 3; it consists of sending an incident volume wave generated by a piezoelectric transducer $(\mathrm{ZnO}$ disc of $75 \mu \mathrm{m}$ 
diameter) which is fabricated on the back of the wafer by lithography process. This same transducer receives also the reflected wave to be analyzed by a signal processor. These reflected signals or echoes could be either the reflection from the top of the pillar $\left(A_{12}\right)$ or from the bottom of the pillars $\left(\mathrm{A}_{11}\right)$ which can give us, after analysis, information about the wetting state [2]. Our characterization method gives good separation of echoes inside the silicon due to the utilization of very small wavelengths of $1.7 \mu \mathrm{m}(\mathrm{f}=5 \mathrm{GHz})$ for the longitudinal waves.

A PDMS micro-channel with dimensions of $3300 \times 3100 \mu \mathrm{m}^{2}$ and thickness of $20 \mu \mathrm{m}$ (Fig. 1 and Fig. 2(b)) is then placed on the silicon DTI structures and aligned on both the acoustic transducer and the silicon DTI structures matrix. The micro-channel is obtained by the realization of a SU-8 photoresist based mold using a laser lithography technique. After several steps (PDMS deposition in the SU-8 mold, annealing and demolding), the micro-channel adhesion to the silicon wafer is established through a surface oxidation of the PDMS (using a corona discharge).

Hydrodynamic calculations have been done to ensure that the pressure loss inside the micro-channel does not exceed 1 bar respecting the conditions that is used in the industry. DTI wafer with etch depth $4 \mu \mathrm{m}$ will be investigated with the use of dynamic flow. The DTI matrix is etched on the silicon wafer front side and consists of nonmetric structures and aspect ratio ranging from 20 to 35 .

Pressure loss and fluid speed inside the micro-channel have been calculated using Eq. 1 [4], and Eq. 2, 3, 4 [5]. Parameters such as fluid speed and height have been obtained from the simulation of fluid film thickness on a rotating silicon wafer as function of distance from the wafer center (Fig. 4). At high rotational speed of wafer $(\omega>800$ r.p.m), Eq. 5 [6] shows very good corresponds with results in Fig. 4, which will be used to calculate the fluid film thickness $(h)$; then we will take our micro-channel height as $2 h$ to achieve the same fluid flow profile, since it is a closed channel compared to the open jet system used in cleaning industrial wafers. Different aspect ratios of DTI $[1,7]$ within silicon wafers, and covered by a PDMS micro-channel, have been tested and subjected to different hydrodynamic conditions. Table 1 show the hydrodynamic conditions on $300 \mathrm{~mm}$ flat wafer and the corresponding pressure loss calculated using Eq. 4 for a micro-channel of $27 \mu \mathrm{m}(2 h)$ in thickness. We can see that the expected pressure loss is small $114.5 \mathrm{mbar}(<1 \mathrm{bar})$ which will not cause problems experimentally and will not cause much difference in micro-channel pressure compared to industrial atmospheric conditions used in cleaning silicon wafers.

$$
\begin{aligned}
& u_{r}=\frac{\omega^{2} r h^{2}\left[1-(1-z / h)^{2}\right]}{2 \vartheta} \\
& f=\frac{64}{R_{e}} \frac{1}{\frac{2}{3}+\frac{11}{24}\left(\frac{b}{a}\right)\left(2-\frac{b}{a}\right)} \\
& D=\frac{2 a b}{a+b} \\
& \Delta P=\rho f \frac{L}{D} \frac{u_{r}{ }^{2}}{2} \\
& h=0.782 \times Q^{0.33} \times v^{0.33} \times \omega^{-0.67} \times r^{-0.67}
\end{aligned}
$$

In the above equations, $u_{r}$ the radial velocity of the fluid $[\mathrm{m} / \mathrm{s}], \omega$ is the rotational speed $[\mathrm{rd} / \mathrm{s}], r$ the radial distance from the wafer center $[\mathrm{m}], z$ is the vertical distance from the surface of the wafer to the top of the fluid film height given as function of $h[\mathrm{~m}], v$ the kinematic viscosity $\left[\mathrm{m}^{2} / \mathrm{s}\right], f$ friction coefficient, $R_{e}$ is the Reynolds number, $a$ and $b$ are the cross sectional dimensions of the micro-channel (width and thickness respectively) [m], $\Delta P$ is the pressure loss from inlet to outlet inside the micro-channel [bar], $\rho$ being the density of the fluid $\left[\mathrm{Kg} / \mathrm{m}^{3}\right], L$ is the length of the micro-channel [m], $D$ is the hydraulic diameter [m], and $Q$ is the flow rate used in industrial process $\left[\mathrm{m}^{3} / \mathrm{s}\right]$. Here we will take the average of the radial velocity so, we will integrate $u_{r}$ as function of $z$ from 0 to $h$ and then divide it by $h$, it will be reduced to Eq. 6 . 


$$
u_{r}=\frac{\omega^{2} r h^{2}}{3 \vartheta}
$$

Table 1: Calculated hydrodynamic conditions applied on $300 \mathrm{~mm}$ wafer for water at $20^{\circ} \mathrm{C}$ and at industrial flow rate of $0.12 \mathrm{~L} / \mathrm{min}$. The corresponding pressure loss is shown for a micro-channel of $27 \mu \mathrm{m}$ in height $(2 h)$.

\begin{tabular}{|lllllll|}
\hline$Q[\mathrm{~L} / \mathrm{min}]$ & $\nu\left[\mathrm{m}^{2} / \mathrm{s}\right]$ & $\omega[\mathrm{r} . \mathrm{p} . \mathrm{m}]$ & $r[\mathrm{~mm}]$ & $h[\mu \mathrm{m}]$ & $u_{r}[\mathrm{~m} / \mathrm{s}]$ & $\Delta P[\mathrm{mbar}]$ \\
\hline 0.12 & $1.0 \mathrm{e}^{-6}$ & 1500 & 140 & 13.50 & 0.21 & 114.50 \\
\hline
\end{tabular}

\section{Results and Discussion}

The DTI [1,7] (Deep Trench isolation) silicon wafer is an etched silicon structure with trenches width of $200 \mathrm{~nm}$, organized as a network of rectangles. Although the DTI wafer is made of silicon, there are two additional layers which are silicon dioxide $\left(\mathrm{SiO}_{2}\right)$ and silicon nitride $\left(\mathrm{Si}_{3} \mathrm{~N}_{4}\right)$ of several tens of nanometers in thickness, present uniquely on the top surface of the trenches. The wetting dynamic on a sample wafer of $4 \mu \mathrm{m}$ etch depth was investigated using distilled water (or mixture of ethanol and distilled water) at $20^{\circ} \mathrm{C}$. The wetting process is measured at different time intervals.

Fig. 5 shows the acoustic reflection using longitudinal waves (frequency $\sim 4.5 \mathrm{GHz}$ ) for three different cases:

- First when no fluid is present in the micro-channel,

- Second when we have an apparent complete filling of the micro-channel and no fluid movement for one minute. This state is called 'static case' one in Fig. 5,

- And finally in the case of dynamic flow through the micro-channel for one minute at a flow rate of $55 \mu \mathrm{L} / \mathrm{min}$ and fluid speed of $4.67 \mathrm{~mm} / \mathrm{s}$. This is called 'dynamic case' in Fig. 5.

The first echo $\left(A_{11}\right)$ occurs at the bottom of the etched silicon at time of $185.1 \mathrm{~ns}$ and the echo from the top $\left(A_{12}\right)$ of the silicon surface occurs at $186 \mathrm{~ns}$. We can observe that $A_{11}$ is the same for all the cases and have a value of $265 \mu \mathrm{V}$ suggesting that no acoustic energy has been absorbed by the presence of a liquid hence, no wetting occurred at the bottom of the trenches. For $\mathrm{A}_{12}$ it is equal to $360 \mu \mathrm{V}$ in the case of no water presence and equal to $297 \mu \mathrm{V}$ for both the static and dynamic case. These latter results suggest that both static and dynamic cases have similar wetting response. In conclusion wetting is not achieved at the bottom of trenches using distilled water both in the static and dynamic cases.

Fig. 6 shows the acoustic reflection response when there is a circulating mixture of ethanol and distilled water $(40 \%$ and $60 \%$ in volume respectively) during one minute through the microchannel, as well as the static state for one minute using this mixture. The flow rate was $38 \mu \mathrm{L} / \mathrm{min}$ and the fluid speed was $3.23 \mathrm{~mm} / \mathrm{s}$ (dynamic case). The first observation is that the two curves, static and dynamic cases, coincide with each other which suggest that there may be no difference in the results between the two states (same results obtained with distilled water). The first echo $\left(\mathrm{A}_{11}\right)$ has a value of $238.1 \mu \mathrm{V}$ in the case of circulating fluid (ethanol + distilled water), while is it $265.7 \mu \mathrm{V}$ where no fluid is present in the micro-channel which suggests the penetration of mixture to the bottom of nano-trenches. The top echo $\left(\mathrm{A}_{12}\right)$ was $259.5 \mu \mathrm{V}$ for the case of mixture and equal to $359.5 \mu \mathrm{V}$ for the case of no fluid present. The impact of the value of $\left(\mathrm{A}_{11}\right)$ implies that this mixture of ethanol and distilled water is able to wet the bottom of the nano-trenches which has not been seen in the case of distilled water. This can be related to the lower surface tension of ethanol. At $20^{\circ} \mathrm{C}$ ethanol has a surface tension of $21.78 \mathrm{mN} / \mathrm{m}$, while that of distilled water is equal to $72.75 \mathrm{mN} / \mathrm{m}$. This lower value makes it easier for ethanol to penetrate high aspect ratio structures and hence induces better cleaning.

Acoustic Reflection Coefficient. Calculation of the acoustic reflection coefficient is done using the acoustic reflection measurements. The acoustic reflection coefficient is defined as the ratio of the acoustic reflection of a surface when fluid is present to the acoustic reflection when no fluid is 
present. Fig. 7 shows the values for two cases; the bottom and top of the DTI trenches. Variation of the reflection coefficient is a direct effect of the mechanical impedance which is related to changing ethanol concentration [8].

We performed an experimental measurement of the contact angle on a flat surface of the DTI wafer (Non-etched surface), and we obtained a value of $60^{\circ}$, which signify that the surface is slightly hydrophilic. In the case of the bottom DTI shown in Fig. 7, with water as the fluid circulating the micro-channel a value of 0.98 has been obtained which suggests that wetting is not achieved. For ethanol concentration between $40 \%$ and $50 \%$ (leading to a surface tension comprises between $26.2 \mathrm{mN} . \mathrm{m}^{-1}$ and $25 \mathrm{mN} . \mathrm{m}^{-1)}$ the reflection coefficient decreases rapidly to 0.89 , then it increases to reach 0.91 for pure $(100 \%)$ ethanol. These values obtained are higher than those obtained by Carlier et al. [9] which are 0.86 to 0.87 for $40 \%$ to $50 \%$ concentration of ethanol and 0.9 for pure ethanol; this suggests that wetting is impartial and non-definitive with ethanol.

For the case of the top surfaces of DTI, the reflection coefficient change in similar manner as in the case of bottom surfaces of DTI, the lower values in this case may be related to the presence of the fluid which absorbs part of the acoustic energy and hence, decreases it. There are two values to explore here, the value of 0.83 for water and 0.79 for the pure ethanol. To explain these values we performed a measurement with static droplet on the flat surface (non-etched surface) of the DTI wafer. The values obtained using the droplet measurements are 0.83 and 0.88 respectively for water and pure ethanol. These values are smaller than what we expect for silicon/water and silicon/ethanol interfaces, which are normally 0.86 and 0.90 respectively. This difference can be related to the presence of other layers on the top of the silicon DTI, namely two layers which are silicon dioxide $\left(\mathrm{SiO}_{2}\right)$ and silicon nitride $\left(\mathrm{Si}_{3} \mathrm{~N}_{4}\right)$ of tens of nanometers each in thickness. These layers are used in the semiconductor industry during the wafer production and etching operation and are present on top of the DTI trenches but, not inside the etched DTI. The presence of these additional layer changes the mechanical impedance of the system (piezoelectric transducer + DTI wafer) which affects the value of the reflection coefficient. For pure ethanol we have a value of 0.79 which is lower than the reference flat surface value 0.88 , this difference could be explained by the presence of fluid inside the DTI trenches due to the lower surface tension of ethanol compared to water, this presence of ethanol absorbs part of the acoustic energy during reflection and hence lower the reflection coefficient.

We can conclude that for the case of the bottom of the DTI structures, the wetting is never totally achieved using distilled water, and is partial and non-definitive in the case of adding ethanol. This could be related to the network pattern collapse Fig. 8 (a), or due to air trapped in the bottom of Vshaped DTI trenches Fig. 8 (b). The results obtained both for the bottom and top DTI requires a simulation code for simulating the acoustic response traversing the different layers of the DTI wafer, so as to obtain the values of the reflection coefficients depending on the state of wetting.

\section{Conclusion}

An experimental bench has been established for the first time wetting characterization using LabOn-Chip integration acoustic transducers/ PDMS micro-channels and DTI structures. The first results show that given conditions (same concentration of water/ethanol mixture), led to the same wetting conditions in static and in dynamic states. We are currently studying the behavior using different mixtures of ethanol and water (therefore intermediate surface tensions), and with different hydrodynamic parameters applied on different aspect ratio structures. Also, a simulation code of the acoustic reflection coefficient inside the silicon wafer is currently being developed, which will enable us to predict the different wetting states. We will also investigate the drying phenomena by injecting gases (air or nitrogen for example). 


\section{Acknowledgements}

This work was supported in part by the STMicroelectronics-IEMN Common Laboratory and in part by the French RENATECH Network on Micro and Nanotechnologies.

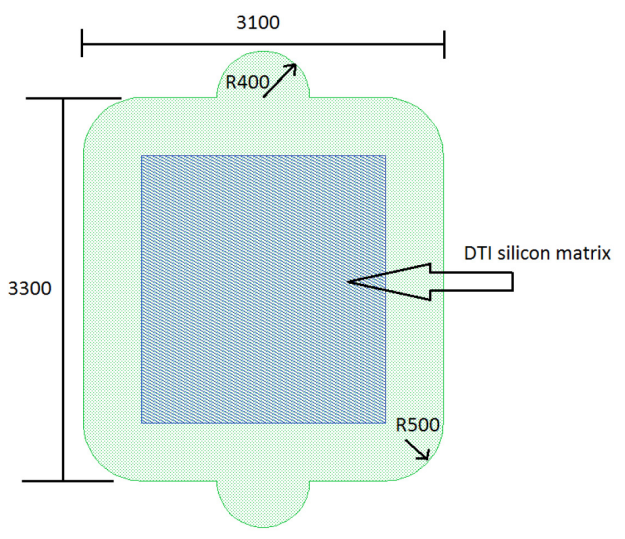

Figure 1: Schematic drawing of the PDMS micro-channel with dimensions given in micrometers.

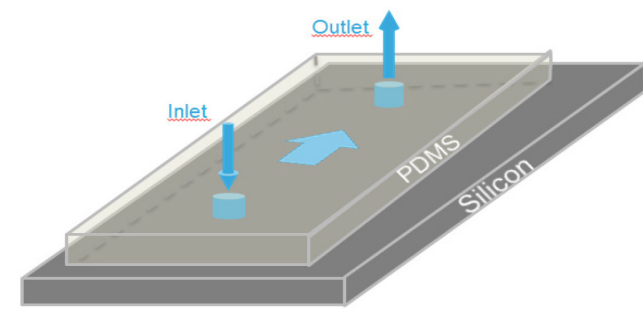

(a)

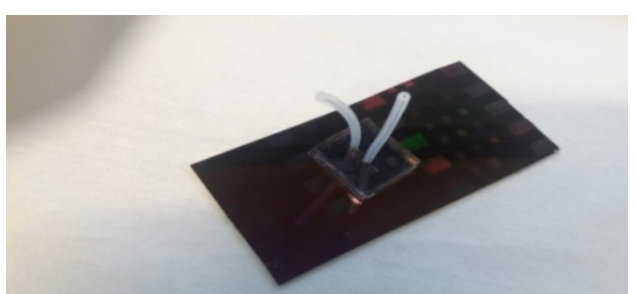

(b)

Figure 2: (a) Scheme of the PDMS micro-channel placed on silicon wafer and (b) PDMS microchannel with inlet and outlet tubes placed on a DTI structured silicon wafer.

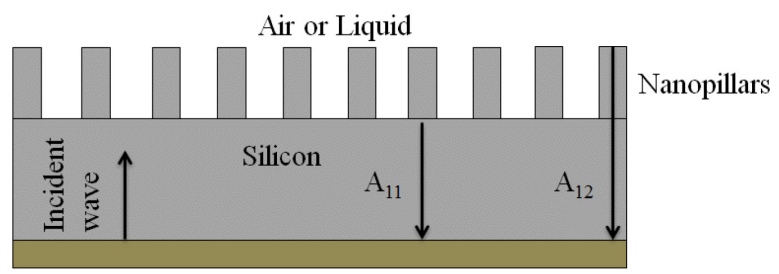

Piezoelectric Transducer

Figure 3: Emission and reception of acoustic wave through silicon using piezoelectric transducer fabricated on the back of the wafer. 


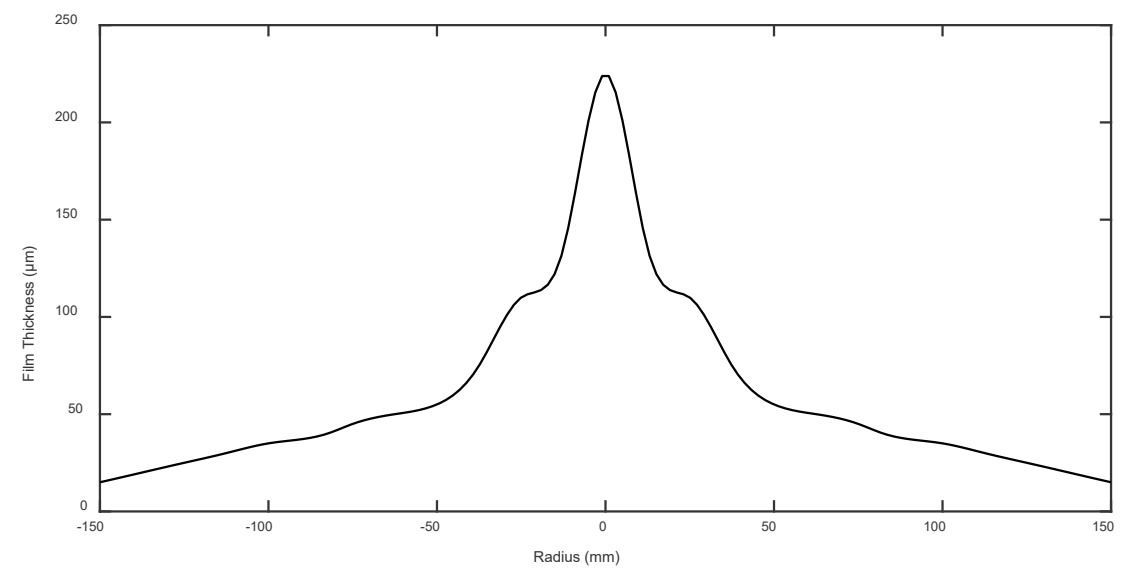

Figure 4: Simulation of the fluid film thickness (h) on a flat rotating silicon wafer (without DTI trenches) as function of the distance from the wafer center for rotating speed of 1000 r.p.m. [10]

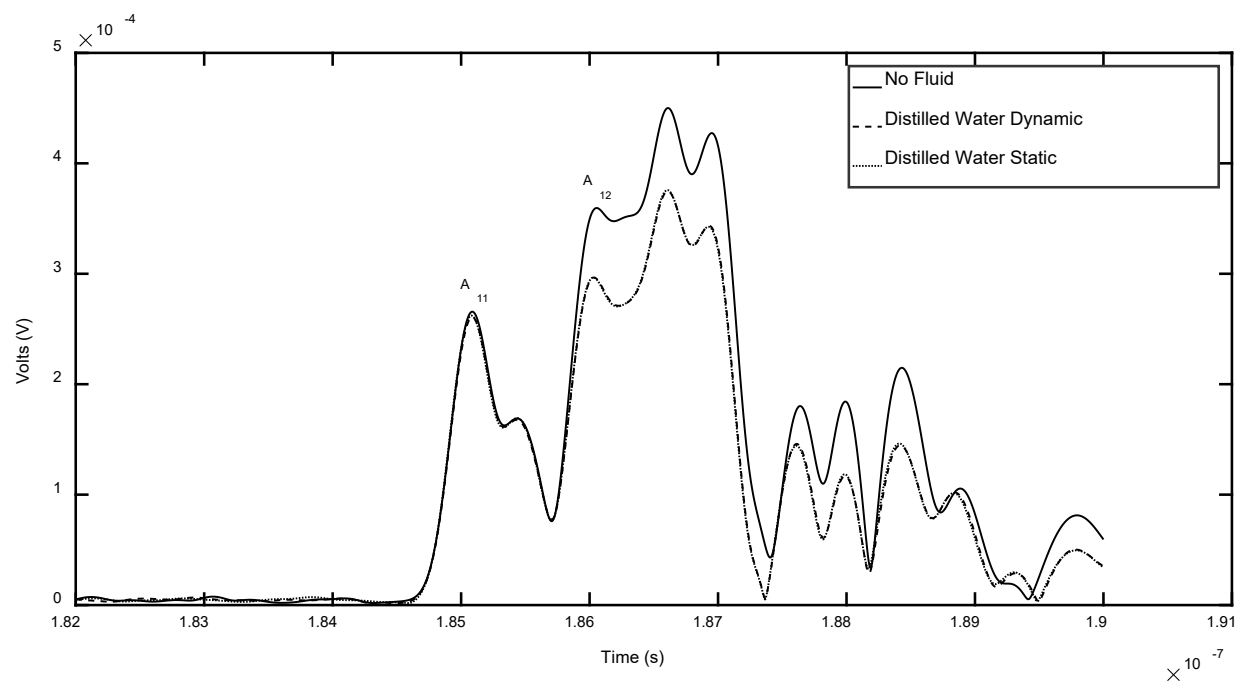

Figure 5: Acoustic reflective wave response off the DTI matrix using longitudinal waves and distilled water as fluid in both dynamic (fluid moving) and static (fluid present not moving inside micro-channel).

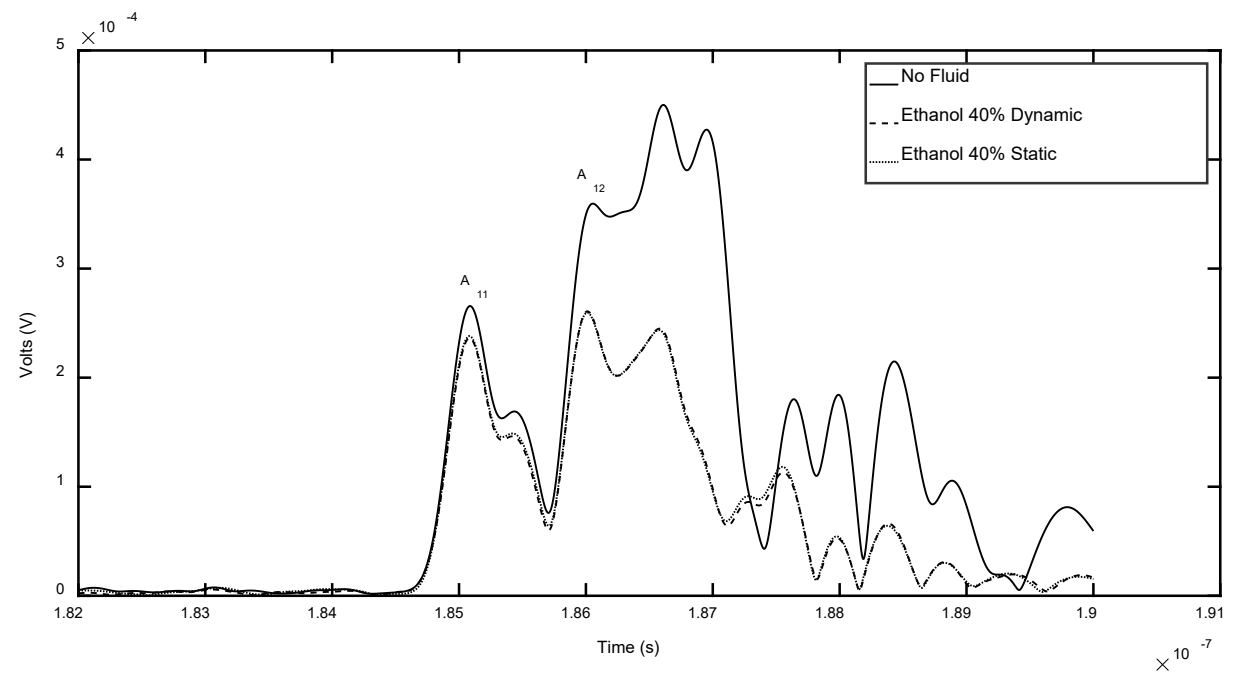

Figure 6: Acoustic reflective wave response off the DTI matrix using longitudinal waves and a mixture of ethanol and distilled water $(40 \%, 60 \%)$ as the fluid in both dynamic (fluid moving) and static (fluid present not moving inside micro-channel). 


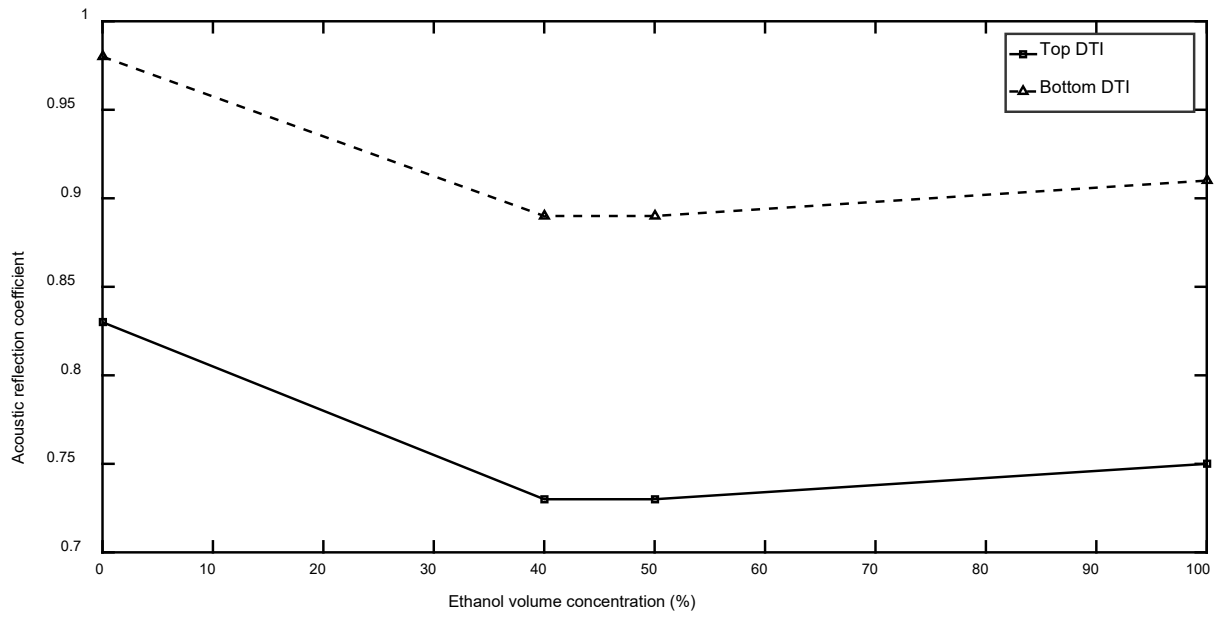

Figure 7: Experimental measurements of the acoustic reflection coefficient on the bottom and top of the DTI using different ethanol/water mixtures.

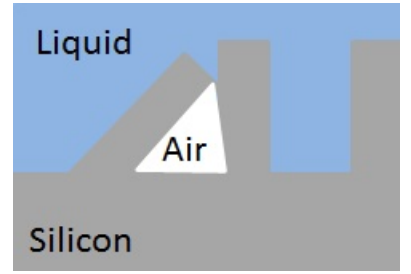

(a)

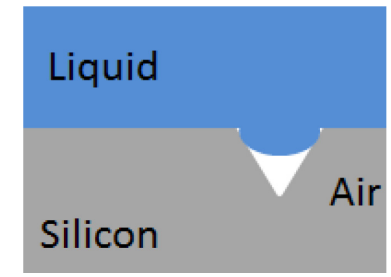

(b)

Figure 8: Scheme of DTI trench network collapse pattern (a) and scheme of a V-shape DTI trench.

\section{References}

[1] P. Garnier, F. Dignat, C. De Buttet, ECS Transactions, 2017, vol 80, pp. 101-109.

[2] C. Virgilio, J. Carlier, P. Campistron, M. Toubal, P. Garnier, L. Broussous, V. Thomy, B. Nongaillard, Journal of Mechanical, Aerospace, Industrial, Mechatronic and Manufacturing Engineering, 2016, vol 10, no 3, pp. 484-489.

[3] S. Li, S. Lamant, J. Carlier, M. Toubal, P. Campistron, X. Xu, G. Vereecke, V. Thomy, B. Nongaillard, Langmuir, 2014, vol 30, pp. 7601-7608.

[4] D. Zamani, K. Dhane, O. Mahdavi, M. McBride, J. Yan, F. Shadman, Microelectronic Engineering, 2013, vol 108, pp. 57-65.

[5] J. Wehking, University of Central Florida, Electronic Theses and Dissertations 3696, 2008, pp. 23-32.

[6] I. Leshev, G. Peev, Chemical Engineering and Processing, 2003, vol 42, pp. 925-929.

[7] C. Virgilio, L. Broussous, P. Garnier, J. Carlier, P. Campistron, V. Thomy, M. Toubal, P. Besson, L. Gabette, B. Nongaillard, Solid State Phenomena, 2016, vol 255, pp. 129-135.

[8] Royer, D., Dieulesaint, E., \& Gennes, P.-G. . (1996). Ondes élastiques dans les solides: Tome 1. Paris: Masson.

[9] J. Carlier, M. Toubal, S. Li, P. Campistron, D. Callens, V. Thomy, V. Senez, B. Nongaillard, Physics Procedia, 2015, vol 70, pp.459-462.

[10] M. Foucaud, Université Grenoble Alpes, Theses and dissertations, Hal Id: tel-01215598, 2015, pp. 123-127. 